3. The use of contraceptive measures. This means either one or other of the following:-

(a) Coitus interruptus. This implies a great deal of self-control, and is possibly not without physiological injury to both husband and wife. It is also "unnatural" and has actually been stigmatised as "legalised masturbation."

(b) Restriction of intercourse to the midmenstrual period. Coarsely put this means that instead of sexual union being the spontaneous culmination of love it must be arranged to a time-table. It is uncertain and "unnatural."

(c) Douching. This is again uncertain in its effects and is not unattended with danger.

(d) The use of such things as quinine pessaries, a small sponge saturated with soap powder, injections of olive oil, etc.; though probably effective these require forethought and care and, in the eyes of the strict moralists, amount to definite "sin."

(e) The use of a sheath or condom by the male. This is not always effective and is similar in its moral aspects to the last-mentioned preventive.

(f) The wearing of a "cap" or pessary by the female, perhaps coupled with the use of quinine pessaries and the like. This is usually effective, but it is on the same level as (d) and (e) morally.

The argument that the use of contraceptive methods is adopted to enable the couple to indulge their sexual appetites is not a fair one and is one that can only be used by those who hold the view that sexual intercourse is permissible only for the purposes of procreation. No one denies that sexual excess is accompanied by its own penalties. On the other hand, the reason why some people do not use contraceptive methods is that they have become so wanting in self-control that they do not wait to consider possible consequences and are guilty of want of forethought and self-control or selfdenial: the selfish accomplishment of a desire is all that matters for the moment and the consequences are left to themselves. Is this moral or immoral ?

We all know from our daily work that where one meets with insanitary management of the home, coupled with poverty and general squalor there you will, in the majority of cases, also find the largest families. It surely is axiomatic that in the inferior grades of the population the greater the number of children in the family the less care and nurture each will receive.

For parents to have more children than they can properly support and maintain is now regarded as a real social evil. It has led to the proposition that the State should be called on to take over the maintenance of all poorly born children. This would be a serious catastrophe in my opinion, for it would lead to a greater propagation of the classes of inferior grade, besides undermining parental responsibility, to say nothing of the burden on the rates.

The remedy suggested for the correction of this high birth rate amongst the inferior grades, viz., that the superior grades should be urged to multiply their kind, is one which I do not think will ever materialise. The superior grades know too much of the advantages of small families ever to revert to the large family.

It was an obscure writer (Martin) who said "Reforms are generally most unpopular where most needed." My hope is that this reform will be received and discussed in a calm, logical and rational fashion from every possible point of view, though I cannot but feel - to quote the Rt. Hon. J. R. Clynes-that "taxes or no taxes, unless we strive for national strength in terms of quality rather than quantity our other social reforms will be merely a waste of time."

\section{NOTES ON THE WORKING OF THE MIDWIVES ACTS AND RULES.}

BY

T. Eustace Hill, M.D., County Medical Officer for Durham.

When introducing discussion on the above at a meeting of the County Mcdical Officers of Health Association held on 9th March, 1923, Dr. Eustace Hill said that, however good they may be, no Acts or Rules can be effective unless those practising midwifery are capable and experienced. At present many medical men when they enter into general practice are not sufficiently trained or experienced in obstetrics, and the same applies to many midwives on obtaining their C.M.B. Certificate. The large number of deaths among women at childbirth and the particularly heavy mortality from puerperal sepsis is a reffection on the practice of midwifery in this country. There is very little doubt that much of the puerperal sepsis is the result of the use of instruments and manipulative interference at birth.

In the Administrative County of Durham statistics indicate that there is a higher maternal mor- 
tality at childbirth where a doctor or certified midwife is in attendance than in cases where no doctor or midwife was in attendance at the birth. This is, of course, largely due to the fact that the majority of the births attended by uncertified women are at normal confinements, and that where an uncertified woman is in attendance and is in difficulties she calls in a doctor or midwife, who then takes over the case, but it is quite certain that a very large proportion of the high maternal mortality, and especially that from sepsis, is preventable.

Another point is that the midwifery service of this country is inadequate in many districts, as is also the accommodation in Maternity Homes and Hospitals. The absence of these Homes and Hospitals increases the difficulty of providing practical training in midwifery for medical students. In Durham Administrative County over 2,500 births were unattended by doctors or midwives during the year 1922 , and only 30 per cent. of the total births were attended by midwives. Unfortunately in some areas medical practitioners do not look with favour on midwives who start practice in their districts, and it is not uncommon to find medical practitioners lending countenance to the practice of midwifery by uncertified women.

\section{SUGGESTED AMENDMENTS TO} MIDWIVES ACTS AND RULES.

MIDWTVES ACT, 1902.

Omit words "habitually and for gain " in Section 1 (2). Alter words "Under direction of qualified medical practitioner " to "Under personal direction and in the presence of a qualified medical practitioner."

Extend Section by making it compulsory for an uncertified woman when called in in an emergency to immediately summon a qualified medical practitioner or midwife.

Section 6 (2).

MIDWIVES ACT, 1918.

Amend Section by making compensation compulsory where midwife has been financially damaged owing to her being suspended from practise, on a charge which is not proved.

Section 14.

It is a matter for consideration whether the fees laid down to be paid to medical practitioners called in by midwives under the Rules of the Central Midwives Board should not be modified. There is an extraordinary difference in the amount of fees paid to medical practitioners in the same areas with similar practices. In one district during a single year, out of five doctors in general practice, one practitioner received over $\& 190$ in one year, another received $£ 49$, another received $£ 1$, and two received nothing, and a similar disparity is noticeable in other areas. Moreover, some midwives send for medical help in a much larger proportion of their cases than do others, and there is reason to believe that some midwives call in a particular medical practitioner, whether the practitioner is the usual medical attendant of the patient or not. In considering the adequacy of the fees paid to medical practitioners under this Section it must be remembered that the medical practitioner has the advantage of the midwife's assistance; his length of stay at the confinement is usually less than if he attended the case from the beginning, and the payment of the fee is a certainty. The fee of two guineas is undoubtedly ample.

It is also a question for consideration whether the fee for a visit to mother and child under Item (5) of the Scale should only be payable in connection with the first visit, payment for subsequent visits being made by the patient or those responsible for her. In some districts, particularly in the North of England, the doctor has entered into a contract to attend the members of the family, and certainly in such cases, only for the first visit should a fee be payable. Prior to the year 1919 in the Administrative County of Durham the annual number of instances where medical help was sought by midwives averaged 372 . During 1919 , the first year during which Section 14 of the Midwives Act, 1918, operated, the cases for which medical help was sought by midwives numbered in successive quarters, $110,164,239,327$. During 1922 the calls numbered 1,498 , and the fees paid by the County Council to medical practitioners in respect of these calls amounted to $£ 2,230$. In Durham there were at the end of 1922, 197 midwives in practice. Comparing these figures for Durham, it is interesting to note that Lancashire County Council with 662 midwives only paid $£ 621$ in fees to medical practitioners, Staffordshire with 309 midwives paid $£ 512$; Yorkshire West Riding with 550 midwives paid $£ 302$, Derbyshire with 370 midwives paid $\$ 268$, and Glamorgan with 558 midwives paid $£ 111$.

In connection with the payment of fees to doctors, it should be laid down as a condition of payment that the doctor should render his account within one month of the date of attendance and also state in connection with each case in which a fee is payable particulars of the services rendered by him.

THE RULES OF THE CENTRAL MIDWIVES BOARD.

Rule E. 19 , relating to the administration of 